\title{
ENSINO DO PORTUGUÊS COMO SEGUNDA LÍNGUA PARA O ALUNO SURDO
}

\section{Gleides Roberta Guerra}

Resumo: Este trabalho propóe compreender, do ponto de vista linguístico, como se dá a aquisição da Língua Portuguesa escrita pelo aluno surdo e as dificuldades e evoluçôes apresentadas por alunos do Ensino Fundamental II em suas produçôes. Para isso, partimos da análise de produçóes escritas realizadas por alunos surdos do $6^{\circ}$ ao $9^{\circ}$ ano do Ensino Fundamental de uma Escola Especial em que a Língua Portuguesa atua e circula como segunda língua. A análise dos textos nos leva a considerar que a LIBRAS náo só é uma língua como também possui estrutura e características próprias inerentes a ela.

Palavras Chave: Português como Segunda Língua. Produção Escrita. Surdez.

\begin{abstract}
The purpose of this research is to understand, from the linguistic point of view, how the deaf student learns written Portuguese and the difficulties and evolutions presented by students from the Elementary School in their productions. In order to get these results, we started from the analysis of written productions by deaf students from the Elementary School of a Special School which Portuguese is the second language. The analysis lead us to consider that LIBRAS is not just a language as it have structure e characteristics of itself.
\end{abstract}

Key words: Portuguese as Second Language. Written Production. Deafness.

1. Mestre em distúrbios da comunicação humana. Fonoaudióloga, Pedagoga e Neuropsicopedagoga, Especialista em educação especial e LIBRAS, Especialista em linguística e língua portuguesa, Professora do Eixo Humanas do Centro Universitário São Camilo, Professora dos cursos de pedagogia e psicologia da Universidade Paulista - UNIP. E-mail: gleidisguerra@hotmail.com 


\section{INTRODUÇÃO}

Historicamente, poucas são as hipóteses que explicam a origem da linguagem. Segundo Faraco (s.d.), atualmente trabalha-se com duas hipóteses, a de que havia uma única manifestação da linguagem verbal da qual derivam as outras (monogênese) e a de que houve vários idiomas no início da humanidade (poligênese).

Saussure (1999) diz que o mais importante sistema de signos é a língua. Ainda relata que a sociedade se organiza em torno deste poderoso sistema, complexo e sem igual no nosso tempo e espaço.

Sabemos que a linguagem é inerente ao ser humano, mas que a língua é aprendida a partir das interações sociais que se estabelece. É a partir desta interação que aprendemos o sistema de comunicação, compartilhamos informaçóes e construímos a nossa identidade. Sendo assim, a Língua Brasileira de Sinais (LIBRAS) também deve ser compreendida desta forma.

Guerra (2005) refere que o grande desafio na educação do surdo relaciona-se ao fato de os alunos terem que aprender uma língua da qual não são usuários, e para isso precisam compreender sua estrutura gramatical e outras peculiaridades não encontradas nas línguas de sinais.

Acreditando que a Língua de Sinais é a língua natural do surdo, a única que ele pode aprender espontaneamente, e que esta cumpre com todos os requisitos fonológicos, sintáticos, morfológicos, semânticos e pragmáticos que todas as demais línguas naturais possuem, este trabalho se propóe a verificar como se dá o processo e evolução da escrita da língua portuguesa do aluno surdo que tem como primeira língua a LIBRAS. É de crucial relevância compreender o papel que o uso da LIBRAS como mediadora do conhecimento desempenha em seu processo de aquisição da escrita, para que, a partir disso possamos considerar suas especificidades e dificuldades com relação a uma segunda língua, no caso a Língua Portuguesa.

Como pedagoga e fonoaudióloga, atuando nas dificuldades de aprendizagem, alfabetização e letramento do aluno surdo, esta pesquisa trará fundamentos para que possamos entender melhor esta forma de aquisiçâo da segunda língua, auxiliando no processo de alfabetização e letramento destes alunos.

A pesquisa poderá auxiliar professores e demais pessoas que trabalhem ou convivam com pessoas surdas compreendendo suas escritas como passiveis de particularidades e especificidades inerentes a sua língua nativa.

Diante dessas consideraçóes, o objetivo deste trabalho é compreender, do ponto de vista linguístico, como se dá a aquisição da Língua Portuguesa escrita pelo aluno surdo. 


\section{UM POUCO DE HISTÓRIA DA LÍNGUA BRASILEIRA DE SINAIS}

D. Pedro II se empenhou em fundar uma escola para surdos no Brasil, pois segundo registros, a Princesa Isabel casada com o conde $\mathrm{D}^{\prime} \mathrm{Eu}$, parcialmente surdo, tiveram um filho com surdez. Em 1855, trouxe para o Brasil um professor surdo, vindo do Instituto de Surdos-Mudos de Paris chamado Hernest Huet para que o trabalho com os surdos fosse atualizado com as novas metodologias educacionais (REIS, 1992).

Reis (1992) relata que em 1911 o INES seguindo uma tendência Mundial estabeleceu o Oralismo em todas as disciplinas. Porém, a Língua de Sinais continuou nas salas de aula, sendo oficialmente proibida apenas em 1957, quando a diretora Ana Rímola de Faria Doria, contando com a assessoria da professora Alpia Couto tomou tal decisão.

Em 1911, seguindo os passos internacionais que em 1880 no Congresso de Milão proibira o uso da língua de Sinais na educação de surdos, estabelece-se que o INSM passaria a adotar o método Oralista puro em todas as disciplinas. Mesmo assim muitos professores, funcionários surdos e ex-alunos que sempre mantiveram o habito de frequentar a escola, propiciaram a formação de um foco de resistência e manutenção da Língua de Sinais (RAMOS, 2011, p. 10).

O mesmo autor relata que em um depoimento informal, uma professora que atuou na escola naquela época encerrando seus trabalhos por lá na década de 80 diz que, apesar das proibiçóes, os sinais nunca desapareceram da escola. Eram realizados em espaços onde não havia fiscalização acontecendo também inclusive embaixo da própria roupa das crianças ou embaixo das carteiras. Mas para o autor, é evidente que este tipo de proibição gera prejuízos irrecuperáveis para uma língua e uma cultura (RAMOS, 2011).

Ainda para o autor, a primeira tentativa de registrar a Língua de Sinais utilizada no Brasil ocorreu em 1869, por meio de um missionário americano chamado Eugenio Oates que publicou um pequeno dicionário de sinais, dicionário das mãos, gerando aceitação de $50 \%$ dos surdos.

Goldfeld (1992) relata que no fim da década de setenta chega ao Brasil a Comunicação Total e na década seguinte o Bilinguismo, partindo das pesquisas da professora Lucinda Ferreira Brito sobre a Língua Brasileira de Sinais, passando a partir de 1994 a utilizar a abreviação LIBRAS (Língua Brasileira de Sinais) criada pela própria comunidade surda.

Segundo Ramos (2011), em 2002 a LIBRAS foi reconhecida e aceita nacionalmente como meio legal de comunicação. Isto se deu a partir da assinatura da Lei número 10.436 em 24 de Abril de 2002. 
Segundo Ramos (2011) a LIBRAS é uma língua de modalidade gestual-visual utilizada como canal ou meio de comunicação, através de movimentos manuais e expressôes faciais e corporais percebidos pela visão, diferenciando-se, portanto da Língua Portuguesa por ser esta uma modalidade oral-auditiva e que utiliza como canal ou meio de comunicação sons que são percebidos pelos ouvidos. Cada língua tem características gramaticais e estruturais próprias.

Para que as Línguas de Sinais fossem reconhecidas como línguas naturais, as semelhanças existentes entre as mesmas e as línguas orais foram avalizadas. Uma das semelhanças encontradas foi a existência de unidades mínimas formadoras de unidades complexas, observadas em todas as Línguas de Sinais encontradas pelo mundo, possuidoras dos níveis fonológicos, morfológicos, sintáticos, semânticos e pragmáticos. (RAMOS, 2011).

Um dos primeiros pesquisadores foi Willian Stokoe que ao publicar seu primeiro livro em 1960 comprova que a Língua Americana de Sinais possuía todos os elementos linguísticos necessários para ser considerada de fato uma língua. $\mathrm{O}$ mesmo autor ainda aponta a importância de considerarmos além das mãos, os movimentos de cabeça e corpo, bem como as expressóes faciais, como portadores de informaçôes linguísticas.

\section{CONCEPÇÃO DE ESCRITA E INTERLÍNGUA}

Para muitos autores, a escrita ocorre por meio de uma representação gráfica advinda da língua oral, em outras palavras, é um processo de evolução em que a linguagem oral, uma vez formada, passa a dar espaço para uma representação gráfica: a escrita.

A escrita é um simbolismo de segundo grau, uma vez que se forma por um sistema de signos que identificam convencionalmente os sons e palavras da linguagem oral que são por sua vez, signos de objetos e relaçóes reais. (MELLO, 2005, p.15).

Segundo a autora, para que a aquisição se dê de forma efetiva, é preciso que o nexo intermediário representado pela linguagem oral desapareça de forma gradual dando espaço a escrita através de um sistema de signos que simbolizem diretamente os objetos e as situaçôes designadas.

Há certa polêmica quando se discute a superioridade de uma modalidade (escrita) sobre a outra (oral). Além disso, alguns autores levantam que toda língua natural tem como propriedade fundamental a oralidade, o que justificaria a sua não inferioridade.

Para Felix (2008), a escrita é uma das formas superiores de linguagem e que requer que a pessoa seja capaz de conservar a ideia que tem em mente, ordenando-a numa determinada sequencia e relação. Ainda segundo a autora, escrever significa relacionar o signo verbal a um signo gráfico, planejando e esquematizando a colocação correta das palavras no papel. 
José e Coelho (1990) consideram no desenvolvimento gráfico o desenvolvimento da linguagem oral. Para eles, a criança precisa falar corretamente os sons das palavras, ter desenvolvidas as habilidades de orientação espacial e temporal, memória visual e auditiva e motivação para aprender.

Porém para Perlin (2010), no caso de pessoas surdas, não há como se utilizar de signos ouvintes, como, por exemplo, a epistemologia de uma palavra. Para ela o surdo só irá entender dentro de signos visuais. $\mathrm{O}$ mesmo acontece com a pronúncia do som de palavras. Segundo a autora, não adianta dizermos que o surdo aprende a escrever da mesma maneira que os ouvintes, uma vez que o pensamento visual da escrita é um dos aspectos que o surdo se serve constantemente.

O processo de aquisição de uma segunda língua, o português para o surdo ou uma língua estrangeira para o ouvinte, passa por diferentes estágios denominados interlíngua. Para Quadros (2006, p. 34), “as crianças surdas apresentarão um sistema que não mais representa a primeira língua, mas ainda não representa a língua-alvo”.

No início da aprendizagem, o aluno surdo apresenta características que misturam a estrutura da primeira e da segunda língua. Ainda assim, a interlíngua não deve ser considerada como confusa ou desorganizada, mas sim como parte do processo de aprendizagem. Para Brochado (2003) este processo é evidente na aprendizagem de alunos surdos fluentes em Língua de Sinais.

Pereira (2009) afirma que é comum as crianças surdas escreverem na língua portuguesa obedecendo a estrutura gramatical da língua de sinais.

Brochado (2003) apresenta os diferentes níveis de interlíngua pelo qual a criança surda passa até chegar à escrita formal do português. Para a autora, o estágio denominado interlíngua I se caracteriza pelo uso de estratégias da Língua de Sinais (L1) para a escrita do Português (L2), havendo, por exemplo, uso de verbos no infinitivo, omissão de artigos, preposiçóes e outros conectivos, uso de construções de frases tipo tópico-comentário.

No estágio Interlíngua II observa-se que embora ainda haja uma mescla das duas línguas, já é possível verificar alguns elementos da Língua Portuguesa, caracterizando uma justaposição entre L1 e L2. Já no Interlíngua III, os alunos demonstram o uso predominante das estruturas da Língua Portuguesa (L2), estruturas frasais complexas, uso de artigos, preposiçôes entre outros. (BROCHADO, 2003).

O autor acredita que as dificuldades apresentadas no processo de aquisição da leitura e da escrita pelo aluno surdo se dá devido às diferenças linguísticas e culturais apresentadas. Ainda neste sentido, Quadros (1999) afirma que o ensino do português para os surdos brasileiros se baseia no processo de alfabetização dos alunos ouvintes, e por isso terminam em fracasso.

De acordo com o Censo Escolar (INEP, 2012), no Brasil, o número de estudantes surdos na Educação Básica e Ensino Superior totaliza 80.207, dos 5,7 milhóes de surdos pesquisados pelo IBGE em 2000, e a maioria destes estudantes surdos, mesmo após passar parte de sua vida dentro 
da escola (10 a 15 anos), não sai do estágio de interlíngua II. Sáo poucos os que conseguem chegar ao estágio de interlíngua III.

Segundo Pereira (2009) o pouco conhecimento da língua portuguesa e de mundo que os alunos surdos possuem limita as possibilidades de compreenderem um texto atendo-se somente a palavras isoladas como no caso da Língua de Sinais.

Ainda para Pereira (2009) a Língua de Sinais tem papel fundamental na aquisiçáo da escrita para crianças surdas uma vez que permite que não só a escrita se torne significativa como também que elas constituam seu conhecimento sobre a Língua Portuguesa escrita por meio da observação entre as semelhanças e diferenças com a Língua de Sinais.

A libras é adquirida pelos surdos brasileiros de forma natural mediante contato com sinalizadores, sem ser ensinada, consequentemente, deve ser sua primeira língua. A aquisição dessa língua precisa ser assegurada para realizar um trabalho sistemático com a L2, considerando a realidade do ensino formal. A necessidade formal do ensino da língua Portuguesa evidencia que essa língua é, por excelência, uma segunda língua para a pessoa surda (QUADROS, 1997, p.84).

Segundo Salles et al. (2004) recomenda-se que a educaçáo dos surdos se efetive na Língua de Sinais independentemente dos espaços em que o processo se desenvolva. Paralelamente faz-se necessário também o Ensino da língua Portuguesa como segunda língua com a utilização de métodos e materiais específicos para atendimento das necessidades educacionais dos surdos.

Para Streiechen (2011) durante o período de construção conceitual da escrita, a criança ouvinte passa a relacionar o que é escrito ao que é falado e que essa compreensão por sua vez, a permite construir hipóteses que lhe permitem prever, antecipar e corrigir suas escritas a partir da oralidade. No caso de crianças surdas, por não possuírem resquícios auditivos que a auxiliem na captação da linguagem oral para o bom uso de uma escrita convencional, as chances de praticarem qualquer regulação sonora, seja silábica ou fonética, são nulas.

Segundo a autora, para as crianças surdas usuárias da Língua de Sinais a busca de significaçóes desta língua para produzir a escrita de outra língua é ainda mais complexa.

Esse aspecto segundo ainda a autora deve ser levado em conta e que cabe ao professor procurar identificar as dificuldades apresentadas pelo aluno surdo procurando saná-las de maneira correta e não ofensiva. "Ele fala uma língua e escreve em outra. A Língua de Sinais apresenta gramática e estrutura independentes e diferentes da Língua Portuguesa. Em Libras, não há o uso de preposições, conjunções, artigos e alguns verbos” (STREIECHEN, 2011, p.29).

Sabe-se que devido às diferenças estruturais entre as Línguas de Sinais e as línguas orais não é possível estabelecer relações diretas entre os dois sistemas linguísticos. Por esse motivo, uma das dificuldades apresentadas pelos alunos surdos em relação à sua produção textual em português 
ocorre ao fazer ligaçóes entre palavras, segmentos, oraçóes, períodos e parágrafos, ou seja, a maneira de organizar sequencialmente o pensamento na Língua Portuguesa (SALLES et al., 2004).

Quando entendemos o conteúdo semântico no texto de uma pessoa surda isso indica que a coerência não foi comprometida. $\mathrm{O}$ fato de o texto ser ininteligível não significa que a estrutura não possa ser reorganizada de acordo com as regras da língua em que esta escrita. É responsabilidade de o professor desenvolver maneiras de garantir a aprendizagem de algumas das infinitas possibilidades de (re) estruturação do texto, garantindo um direito alienável do surdo: o acesso a elas (SALLES et al., 2004, p.52).

\section{METODOLOGIA}

Visando demonstrar o processo e evoluçáo da escrita de alunos surdos, analisaremos produções escritas de quatro crianças surdas, do sexto ao nono ano do Ensino Fundamental de uma Escola Especial para surdos do município de São Bernardo do Campo, que ensina a língua portuguesa como segunda língua.

Neste trabalho utilizar-se-á a abordagem qualitativa tendo como principal instrumento o estudo de casos. Consideramos esta abordagem a mais apropriada para pesquisa uma vez que privilegia as experiências e evoluçóes dos sujeitos envolvidos possibilitando-nos uma reflexáo frente ao problema levantado e explicitado através da avaliação realizada que submetidos a analise trouxeram dados significativos que auxiliaram a compreensão da problemática levantada.

Sendo assim, este estudo se dará a partir da avaliação da produção escrita de alunos surdos do Ensino Fundamental II portadores de surdez e usuários da Língua Brasileira de Sinais (Libras) como sua primeira língua.

Os alunos foram analisados com relação ao uso da linguagem escrita através de uma sequência de imagens pré-estabelecidas cuja ideia central se referia ao perigo de se soltar balóes.

\section{FIGURA 1 - HISTÓRIA EM SEQUÊNCIA APRESENTADA AOS ALUNOS}

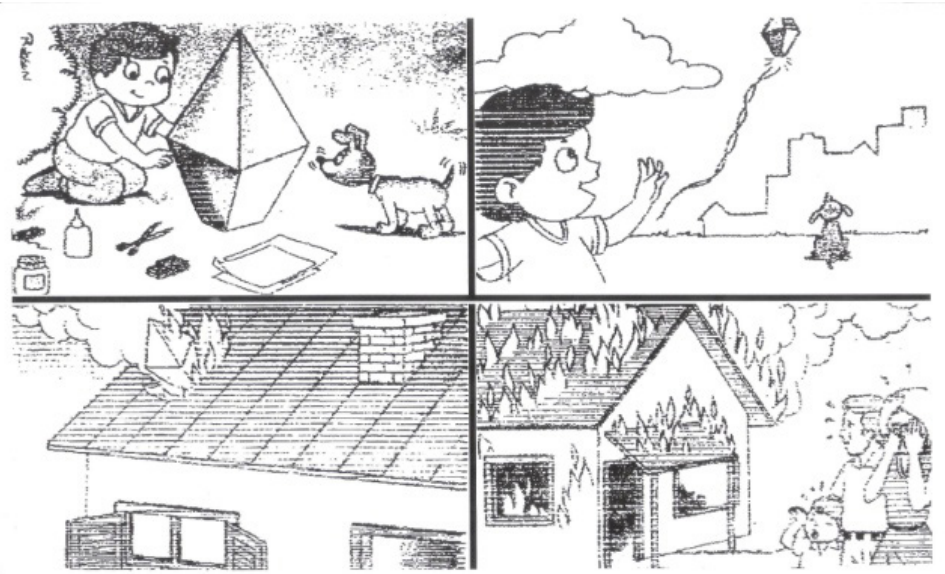


Esta atividade foi escolhida por envolver a produção de um texto e não de palavras soltas, isoladas. Os alunos evidenciaram dispor de conhecimento de língua e de mundo suficientes para atribuir significado as imagens bem como para realizar a atividade proposta.

Por se tratar de uma história em sequência, é esperado que a narrativa realizada levasse em consideraçáo a sequência temporal dos fatos. A proposta é que fosse realizado um texto narrativo, e não apenas descritivo.

\section{RESULTADOS E DISCUSSÃO}

Apresentaremos abaixo as escritas produzidas pelos alunos surdos das diferentes séries, e analisaremos cada uma delas com base no desenvolvimento da língua portuguesa e da interferência da LIBRAS.

O primeiro texto apresentado foi produzido por um aluno do sexto ano do Ensino Fundamental II:

\section{FIGURA 2 - TEXTO PRODUZIDO POR ALUNO DO 6 ANO DO ENSINO FUNDAMENTAL II}

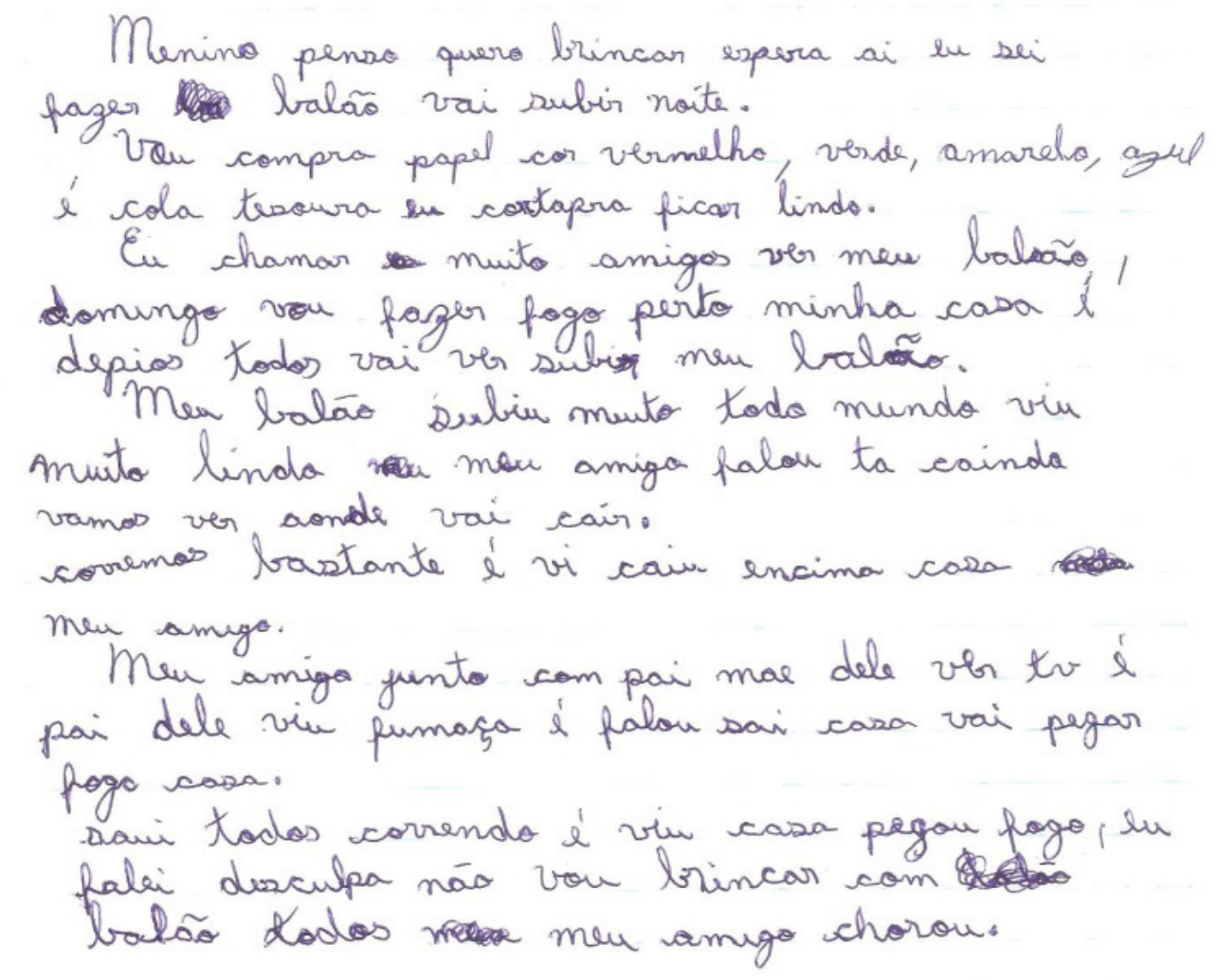


A narrativa apresentou frases simples e às vezes justapostas, com características de aglutinação e omissão de grafemas, faltaram elementos de ligação como conjunçóes, preposiçóes e os verbos nem sempre foram flexionados adequadamente, o que pode ter ocorrido devido ao pouco domínio da Língua Portuguesa pelo aluno surdo, por esta ser uma segunda língua.

Segundo Streiechen (2011) é bastante comum este tipo de alteração linguística, uma vez que, quando se trata da língua oral, é importante lembrar que os surdos são praticamente estrangeiros em seu próprio país. Podemos considerar que este texto (Figura 2) encontra-se no estágio interlíngua II, em que observamos algumas características da L1 e outras da L2 (BROCHADO, 2003).

O texto abaixo foi produzido por um aluno do sétimo ano do Ensino Fundamental II:

FIGURA 3 - TEXTO PRODUZIDO POR ALUNO DO 70 ANO DO ENSINO FUNDAMENTAL II

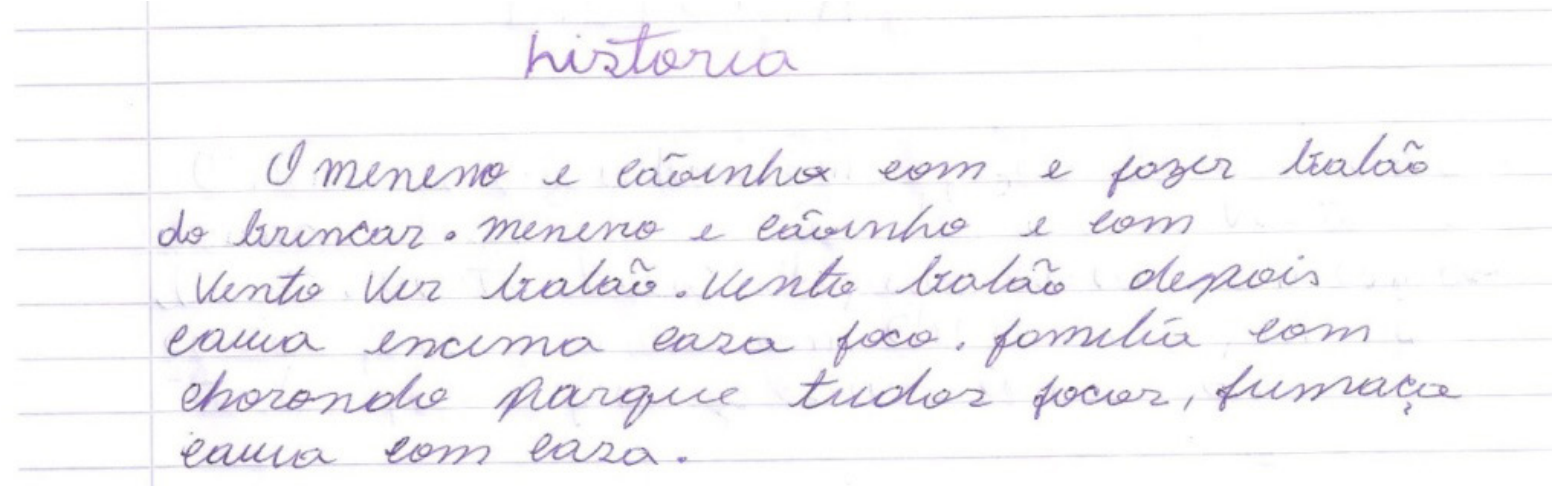

A partir do texto produzido pelo aluno do $7^{\mathrm{o}}$ ano do Ensino Fundamental II (Figura 3), podemos observar que a Língua de Sinais apresenta gramática e estrutura independentes e diferentes da Língua Portuguesa. Em Libras não há o uso de preposições, conjunçôes, artigos e tempos verbais, o que se reflete na produção escrita do aluno surdo. Porém, observamos que do ponto de vista semântico é possível compreender o sentido dado à narrativa.

Mesmo com a mescla ocorrida entre L1 e L2, os textos (Figura 2 e 3) se mostraram perfeitamente compreensíveis. As produções revelam progressos dos alunos no decorrer de seus percursos escolares tanto no que se refere à construção de textos como também quanto ao uso do português. Demonstraram ter compreendido as sequências das imagens e conseguir estruturar narrativa condizente com a imagem.

É importante citar que embora a pesquisa se remeta a evolução da produção escrita no decorrer dos anos escolares, observamos também que este não é o único fator que influencia o desenvolvimento do aluno surdo. Como podemos observar, o texto produzido pelo aluno do sexto ano é superior ao produzido pelo aluno do sétimo ano o que denota características e vivências individuais a cada aluno.

O texto a seguir foi escrito por um aluno do oitavo ano do Ensino Fundamental II: 
FIGURA 4 - TEXTO PRODUZIDO POR ALUNO DO $8^{\circ}$ ANO DO ENSINO FUNDAMENTAL II

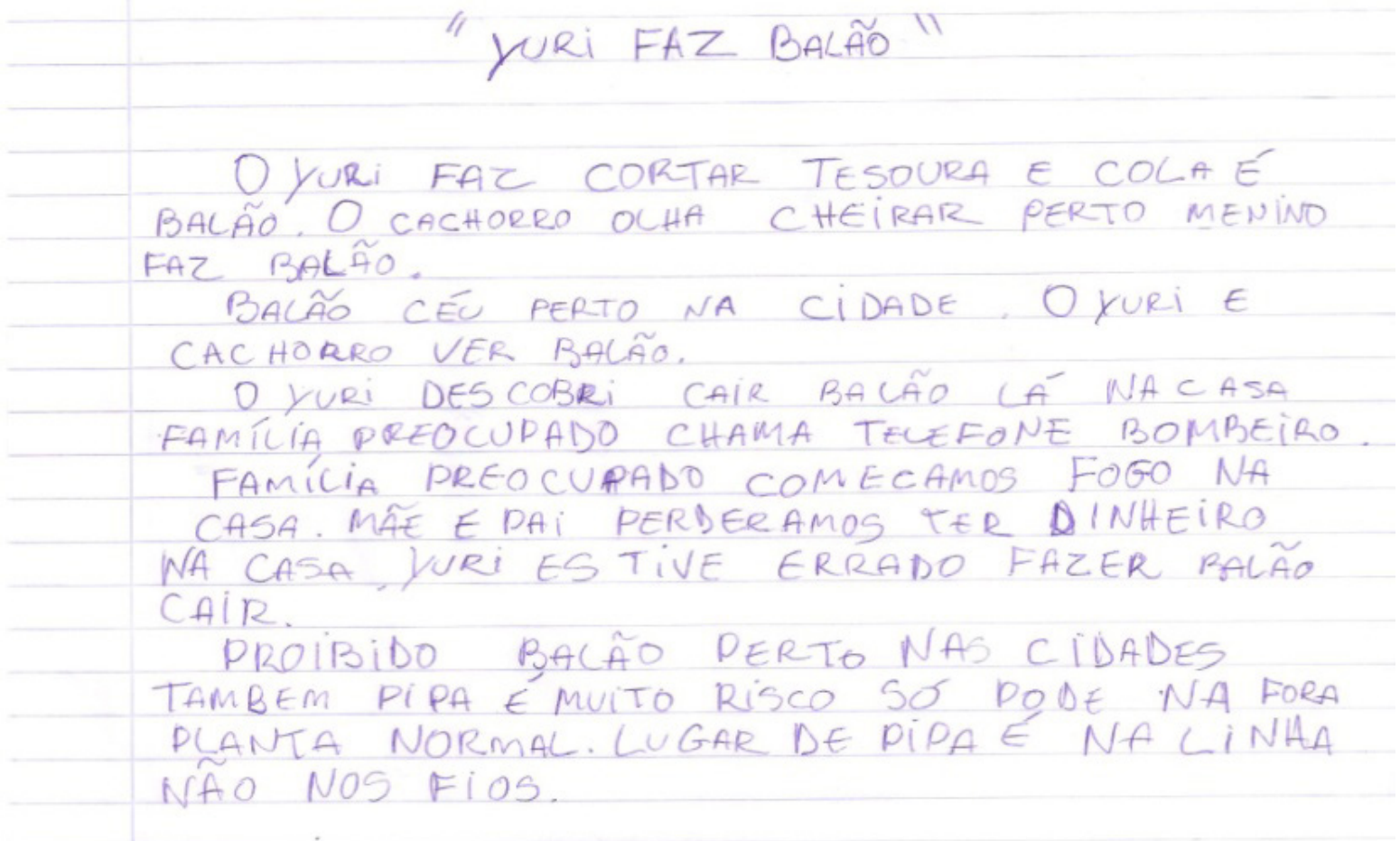

A Figura 4 mostra um desempenho narrativo satisfatório, mas ainda é possível observar a interferência da L1 na produção escrita na L2.

Comparando as diferentes narrativas realizadas pelos alunos, foi possível observar diferença entre elas em relação ao conhecimento e amadurecimento do uso da Língua Portuguesa. Para Fernandes (2008) a diferença encontra-se no fato de os surdos, usuários de LIBRAS, terem oportunidade de aquisiçẫo da linguagem escrita a partir da sua primeira língua.

O último texto foi produzido por um aluno do nono ano do Ensino Fundamental II:

FIGURA 5 - TEXTO PRODUZIDO POR ALUNO DO 9० ANO DO ENSINO FUNDAMENTAL II

Os baioés chamam unvite a atungä por serem unvito bonitos you isso as criargos lgostam de sotiar um balä unas faita de responsabilidade lé les pais das criongas clevem unsinar que as criangas sao proibidos de brincar yporque pode vacorfecer machucados as pessoas vou clestroir de casas entue outras caisas por isso unós yprecisamos que persar unas consiquíncias. Eे mito nersiose I] 
No texto apresentado na Figura 5, podemos observar um proximidade muito grande à escrita formal do português, embora possamos encontrar erros ortográficos e ausência de pontuação. Podemos perceber que este aluno está muito próximo a um estágio de interlíngua III, o que demonstra que o aluno surdo, quando estimulado a partir da sua língua natural, pode conseguir tem uma boa produção escrita da Língua Portuguesa.

\section{CONSIDERAÇÕES FINAIS}

A partir deste estudo pudemos observar a importância para o aluno surdo de ter a Língua Brasileira de Sinais (LIBRAS) como mediadora da aprendizagem da escrita da Língua portuguesa. A Língua de Sinais é a língua natural dos surdos e como sua primeira língua (L1) serve de apoio para que a segunda língua (L2) se desenvolva na modalidade escrita.

Ao observar os diferentes estágios interlíngua pelos quais o aprendiz da segunda língua passa, percebemos a maneira como as duas línguas inicialmente se mesclam para posteriormente a estrutura gramatical da L2 se estabeleça, dando origem à escrita formal do português.

A análise dos textos nos leva a considerar que a Libras não só é uma língua como também possui estrutura e características próprias inerentes a ela.

Cabe ao professor partir de tais conhecimentos, levando-se em consideração o que é significativo ao seu aluno, ensinando-lhes a escrita da Língua Portuguesa sem se esquecer de que esta é a sua segunda língua.

As produções escritas em Língua Portuguesa dos alunos surdos, embora gramaticalmente sofrerem interferência da sua primeira língua (LIBRAS), são cheias de significado, intencionalidade e coerência, na maioria das vezes estruturadas com algumas particularidades inerentes ao aprendizado da L2.

É preciso, portanto, um olhar diferenciado do professor ao ensinar e avaliar a escrita dos alunos surdos, usando de metodologias adequadas, próprias ao ensino de segunda língua.

\section{REFERÊNCIAS}

BRASIL. Censo Escolar 2012. Instituto Nacional de Estudos e Pesquisas Educacionais Anísio Teixeira (INEP). Disponível em www.portalinep.gov.br

BRASIL. Lei n. 10.436, de 24 de abril de 2002. Dispóe sobre a Língua brasileira de sinais-LIBRAS-e da outras providencias. Diário Oficial da Republica Federativa do Brasil, Brasília, 25 de abril de 2002. 
BROCHADO, S.M.D. A apropriaçáo da escrita por crianças surdas usuárias da Língua Brasileira de Sinais. Assis: UNESP, 2003. 431f. Tese (Doutorado em Letras) - Programa de pós-graduação em Filologia e Linguística portuguesa. UNESP, Assis, 2004

FARACO, C.A. A origem das línguas. Revista Science, s.d.

FELIX, C.A. O Processo de aquisiçáo da língua escrita. Revista Educação. Faculdade Anhanguera de Taubaté. Taubaté, vol. XI n.12, ano 2008.

GOLDFELD, M. A criança surda: linguagem e cogniçâo numa perspectiva sócio-interacionista. Ed. Plexus, São Paulo, 1997, 176p.

GUERRA, G.R. A escolarizaçáo do aluno surdo: estudo comparativo entre alunos do ensino regular e ensino especial. 2005. Dissertação (Mestrado em Distúrbios da Comunicação Humana). Universidade Federal de São Paulo, São Paulo, 2005.

JOSE, E.A; COELHO, M.T. Problemas de aprendizagem. São Paulo ed. Ática, 1990.

MELLO, S.A. O processo de aquisição da escrita na educaçáo infantil contribuiçóes de Vygotsky. In: FARIA, A.L.G. e MELLO, S.A. (orgs.). Linguagens Infantis outras formas de leitura. Campinas Autores Associados, 2005, p 23-40.

PEREIRA, M.C. Aquisição da escrita por crianças surdas: início do processo. Porto Alegre: Letronica, jul 2009. p.138-149 V.02, n.01.

PERLIN, G.T.T. Identidades Surdas. In: SKLIAR, C(org.). A surdez: um olhar sobre as diferenças. 4 Ed Porto Alegre. Mediação, 2010.

QUADROS, R. Educaçáo de surdos: a aquisição da linguagem. Porto Alegre. Artes Médicas, 1997. . Ideias para ensinar português para alunos surdos. Brasília: MEC, SEESP, 2006.

RAMOS, CR. LIBRAS: A língua de sinais dos surdos brasileiros. Projeto educação especial inclusiva. Ed. Arara Azul. Rio de janeiro SETRAB/IPPP cap. 42011 12p.

REIS, V.P.F. A criança surda e seu mundo: o estado-da-arte, as políticas e as intervençôes necessárias. Dissertação de mestrado. UFES, 1992.

SALlES, H.; FAULSTICH, E; CARVALHO, O.L; RAMOS, A.A.L. Ensino de Língua Portuguesa para Surdos-Caminhos para a prática pedagógica-programa Nacional de Apoio à Educação dos Surdos. Ministério da Educação. Secretaria de Educação Especial, Vol. 1 e vol. 2. Brasília, 2004.

SAUSSURE, F. Curso de Linguística Geral. Trad. Antônio Chelini, José Paulo Paes e Izidoro Blikstein. 25.ed. São Paulo: Cultrix, 1999.

STREIECHEN, E.M. Por que o surdo escreve diferente? Revista Interlinguagens. Universidade Estadual do Centro-Oeste-UNICENTRO, v. 2, n.02, 2011. 